\title{
OPEM
}

www.opem.org

Oriental Pharmacy and Experimental Medicine 2008 8(2), 192-195

DOI 10.3742/OPEM.2008.8.2.192

\section{Evaluation of antifilarial activity of Berberis aristata roots}

\author{
Waseem Rizvi ${ }^{1, *}$, Anil Kumar ${ }^{1}$, Razi Ahmad ${ }^{1}$, Mohammad Shahid ${ }^{2}$, Anwar Shazad ${ }^{3}$ and Nakhat \\ Haider $^{4}$ \\ ${ }^{I}$ Department of Pharmacology J. N. Medical College, Aligarh Muslim University, Aligarh, (UP), India; ${ }^{2}$ Department of \\ Microbiology, J. N. Medical College, Aligarh Muslim University, Aligarh, (UP), India; ${ }^{3}$ Department of Botany, \\ Aligarh Muslim University, Aligarh, (UP), India; ${ }^{4}$ University Health Service, Aligarh Muslim University, Aligarh, \\ (UP), India
}

Received for publication December 12, 2006; accepted October 19, 2007

\begin{abstract}
SUMMARY
The effect of aqueous and alcoholic extract of roots of Berberis aristata was studied on the spontaneous movements of the whole worm (w.w) preparation and nerve muscle (n.m) complex of cattle filarial parasite Setaria cervi and on the survival of microfilariae. Only aqueous extract could inhibit the spontaneous movements of $S$. cervi, characterized by initial stimulation followed by reversible paralysis. The concentration required to produce similar effect on n.m complex was less as compared to the w.w. The lethal concentration 50 and lethal concentration 90 for aqueous extract were $48 \mathrm{ng} / \mathrm{ml}$ and $65 \mathrm{ng} / \mathrm{ml}$.
\end{abstract}

Key words: Antifilarial activity; Berberis aristata; Setaria cervi

\section{INTRODUCTION}

Berberis aristata is an erect, glabrous shrub found in Nepal at an altitude of $6,000-8,000 \mathrm{ft}$. The alkaloids in the bark and root bark of Berberis are berberine, berbamine, aromoline, karachine, palmatine, oxyacanthine and oxyberberine (Chopra, 1982).

In Ayurvedic medicine the roots of B. aristata is reported to possess anti-inflammatory and antibacterial activities, and is used as laxative, diaphoretic, antipyretic, antiseptic and antiulcer agent (Chopra, 1982). Clinical studies with berberine in Cholera patients showed that it was effective in both bacteriologically positive and negative patients, it

*Correspondence: Waseem Rizvi, Department of Pharmacology J. N. Medical College, Aligarh Muslim University, Aligarh, (UP), India. E-mail: waseemrizvi76 @hotmail.com reduces mortality rate, volume and duration of diarrhea (Lahiri and Dutta, 1967; Sharda, 1970). It is also effective in giardiasis (Choudhry et al., 1972) and gastroenteritis in children. Berberine is also known to possess antidiabetic activity (Hua and Wang, 1994; Hua et al., 2001). Despite the medicinal properties of $B$. ariststa the antifilarial activity, especially against S.cervi has not yet been explored. Therefore, the present preliminary study was designed to see the antifilarial potential of aqueous and alcoholic extracts of roots of B. aristata.

\section{MATERIALS AND METHODS}

The shrub was collected from Forest Research Institute (F.R.I), Dehradun, and identified by Dr. Badar Alam Senior Lecturer in the department of Botany, Aligarh MuslimUniversity Aligarh and the 
specimen was deposited in the same department via Herbarium/Account No. 1705.

The dried roots were ground in an electric grinder, the powder obtained was transferred to ordinary filter paper in Soxhlet apparatus, ethyl alcohol was used as a solvent for alcoholic extract whereas distilled water for aqueous extract. The solvent obtained was allowed to evaporate in a vacuum dessicator and after the complete evaporation of the solvent, the residual material was diluted with saline to make a stock solution of $1 \mathrm{mg} / \mathrm{ml}$. Motile adult $S$. cervi (Nematoda filarioidea) of average length $6.0 \pm 1.0$ were collected from the peritoneal cavity of freshly slaughtered cattle and brought to the laboratory in a vacuum flask containing modified Ringer's solution (Sodium chloride $9 \mathrm{~g}$, Potassium chloride $0.42 \mathrm{~g}$, Calcium chloride $0.24 \mathrm{~g}$ Sodium bicarbonate $0.5 \mathrm{~g}$, glucose 0.25 per liter) at $37^{\circ} \mathrm{C}$.

\section{Whole worm (w.w.) preparation}

Adult $S$. cervi were suspended in an ideal isolated organ bath of $20 \mathrm{ml}$ capacity, in modified Ringer's solution at $37^{\circ} \mathrm{C}$. Spontaneous movements of the worm were recorded on a slow moving kymograph drum (Singhal, 1975). Air or Oxygen was not bubbled through the solution, as it did not improve the movements of the worm. Approximately $15 \mathrm{~min}$ were allowed for the movements of worm to stabilize before eliciting the response of drug. The drug was added in increasing concentration to the bath fluid and allowed to remain in contact for $15 \mathrm{~min}$. If there was no response it was considered inactive.

\section{Nerve-muscle (n.m) complex}

A worm was placed in a petridish containing modified Ringer's solution $\left(37^{\circ} \mathrm{C}\right)$. Two dissecting needles were inserted into the worm at one end, and the cuticle was split longitudinally. The intestine and uterus were cut at both ends and removed. The anterior $1 \mathrm{~cm}$ of the worm was removed to eliminate the influence of the nerve ring and cephalic ganglia. The remaining part was tied at either end and suspended in an isolated organ bath, containing modified Ringer's solution at $37^{\circ} \mathrm{C}$. The preparation served to expose the n.m. complex directly to the action of the drugs, and also could exhibit spontaneous rhythmical movements similar to those of the whole worm. The drug concentrations were tested for their response as with whole worm preparation. The concentration of extract, which modified the movements, was tested in at least six preparations.

\section{Collection of microfilariae (m.f.)}

The uterus of a female $S$. cervi was cut at its junction with the vagina just below the bifurcation, and removed from the worm. It was teased with a fine needle in the solution and m.f. were freed. The m.f were suspended in a human serum : Ringer mixture and the m.f. count was adjusted to $100 \mathrm{ml} .0 .5 \mathrm{ml}$ aliquots of the m.f. suspension were placed in sterilized screw capped bottles containing aqueous extract of $B$. aristata in equal serum : ringer mixture (v/v) (Singhal, 1975). Extract was added in doubling concentration from $5 \mathrm{ng} / \mathrm{ml}$. The bottles were kept in an incubator at $37^{\circ} \mathrm{C}$ and examined under a microscope every $30 \mathrm{~min}$ till $6 \mathrm{~h}$ to observe the survival/mortality of microfilariae. The lethal concentration 50 (LC 50) and lethal concentration 90 (LC 90) were calculated from a concentration vs death graph.

In a preliminary set of experiment it was ascertained that the concentration of alcohol/water in the suspending medium did not influence the survival/mortality of the m.f. In a preliminary experiment, the aqueous and alcoholic extract of B. aristata were added to m.f. in concentration of 5 , $10,15,20,25 \mathrm{ng} / \mathrm{ml}$ to determine the limits of activity within $6 \mathrm{~h}$ at $37^{\circ} \mathrm{C}$, within these limits six concentrations were selected to observe the survival of m.f. The effect of each dose was observed 10 times. The mean of the values were plotted on a graph.

\section{RESULTS}

Effect of aqueous extract of B. aristata on the 


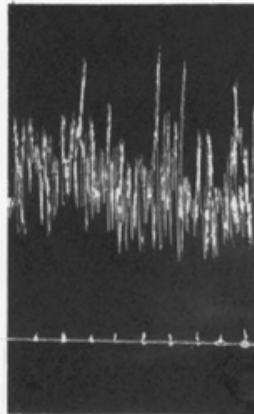

$500 \mu \mathrm{g} / \mathrm{ml}$

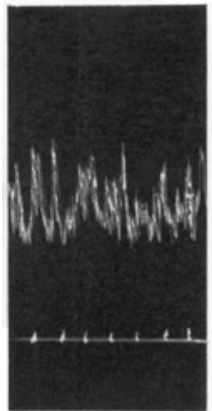

$60 \mathrm{~min}$

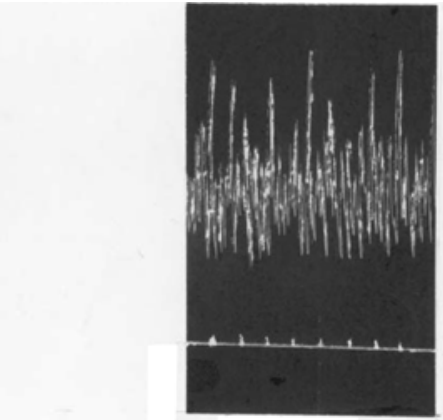

$30 \mathrm{~min}$

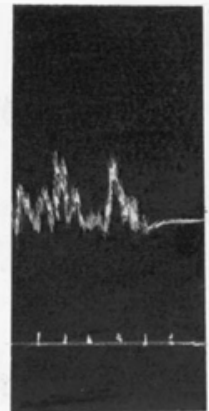

$90 \mathrm{~min}$

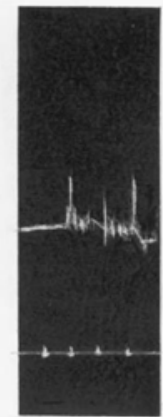

Wash
Fig. 1. The initial stimulatory effect of $500 \mu \mathrm{g} / \mathrm{ml}$ of aqueous extract from roots of Berberis aristata on spontaneous movements of W.W preparation of $S$. cervi leading to reversible paralysis.

spontaneous movements of w.w preparation and n.m complex of S. cervi. On addition of $500 \mathrm{mg} / \mathrm{ml}$ of aqueous extract there was initial stimulation characterized by increase in amplitude and rate of contraction lasting for $30 \mathrm{~min}$ (Upper panel, Fig. 1), followed by a decrease in rate and amplitude at 60 min, leading to complete cessation of movements at $90 \mathrm{~min}$. The motility was reversed on repeated changes of bath fluid ie, the paralysis is reversible in nature (Lower panel, Fig. 1). The response of n.m complex to aqueous extract was different in nature. Addition of $350 \mathrm{mg} / \mathrm{ml}$ of extract to the bath fluid produced inhibition of spontaneous movements characterized by decrease in amplitude and rate of contraction (Upper panel, Fig. 2) followed by complete cessation of movements at 60 mins. The paralysis produced was reversible in nature as repeated changes of bath fluid caused reversal of movements (Lower panel, Fig. 2). The

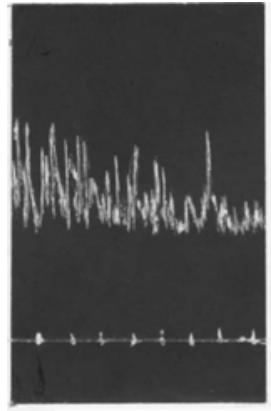

$350 \mu \mathrm{g} / \mathrm{ml}$

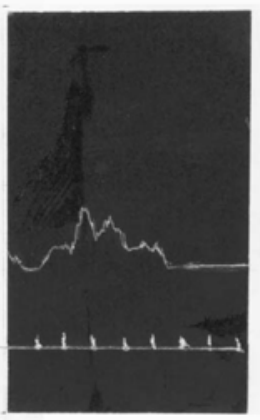

$60 \mathrm{~min}$

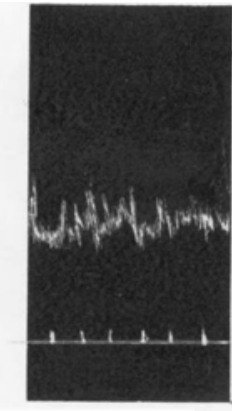

$30 \mathrm{~min}$

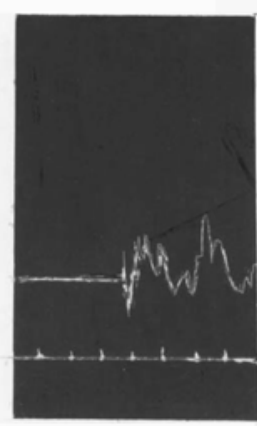

Wash
Fig. 2. Reversible paralysis of movements of n.m complex of $S$. cervi with $350 \mu \mathrm{g} / \mathrm{ml}$ of aqueous extract from roots of Berberis aristata.

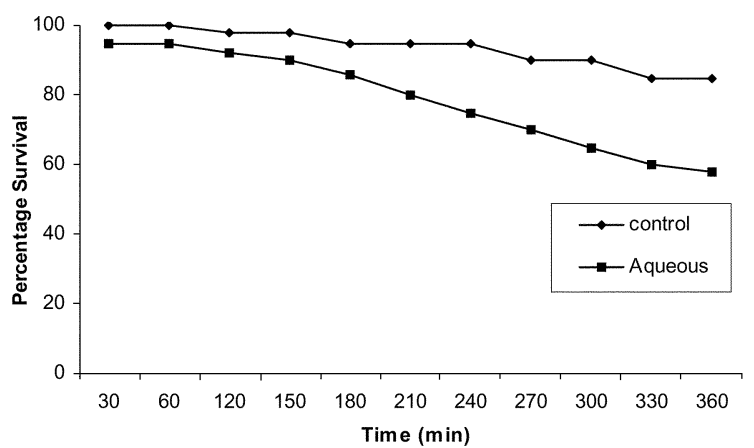

Fig. 3. Survival of m.f of $S$. cervi In vitro at a concentration of $25 \mathrm{ng} / \mathrm{ml}$ of aqueous extract from roots of Berberis aristata.

alcoholic extract failed to produce any effect on the movements of the w.w preparation or the n.m complex. Effect of aqueous extract of B. aristata on the survival of $m . f$ in vitro. Aqueous extract caused a concentration related inhibition of survival of m.f of $S$. cervi. The time related lethal effect at a concentration of $25 \mathrm{ng} / \mathrm{ml}$ is shown in Fig. 3. The LC50 and LC90 observed after $6 \mathrm{~h}$ are $48 \mathrm{ng} / \mathrm{ml}$ 
and $65 \mathrm{ng} / \mathrm{ml}$ respectively.

\section{DISCUSSION}

Aqueous extract of B.aristata produced inhibition of spontaneous movements of both w.w preparation and n.m complex of S. cervi. The concentration required to produce the same effect on n.m complex was less than that required for w.w preparation. This suggests that cuticle can reduce permeation of extract in to the intact filarid. Substance with low lipid solubility penetrate to a lesser extent across the cuticle of the nematode, has been shown for Ascaris (Fetterer, 1986) and Dipetalonema vitae (Christ et al., 1990). The onset of action was rapid in both cases with a difference that there was initial stimulatory phase in case of w.w preparation, this could be due to the irritant effect of extract on cuticle as has been shown with other substances as well (Christ et al., 1990). It has been shown that the nematodes possess both the excitatory (acetylcholine) as well as inhibitory (GABA, 5-HT) neurotransmitters which can paralyse the worm (Singhal et al., 1975). A number of anthelmitics interfere with neuromuscular transmission, like piperazine which mimics the action of GABA and causes hyperpolarization of Ascaris and S. cervi muscle cell (Singhal et al., 1975; Aubry, 1970; Del et al., 1963). Diethylcarbamazine (DEC) a piperazine derivative produces reversible paralysis by antagonizing voltage sensitive potassium channels (Martin, 1982). The aqueous extract of $B$. aristata also produced inhibition followed by reversible paralysis, this response resembles that of DEC (Singhal et al., 1978). To conclude we can say that aqueous extract of $B$. aristata possess potential antifilarial activity having action somewhat similar to that of DEC this can be further confirmed by in vivo studies.

\section{REFERENCES}

Aubry NL Cowell P, Davey MJ, Shevda S. (1970)
Aspects of Pharmacology of a new anthelmintic: Pyrantel. Br. J. Pharmacol. 38, 332-344.

Christ D, Goebel M, Saz HJ. (1990) Actions of acetylcholine and GABA on spontaneous contractions of filarid Dipetalonema viteae. Br. J. Pharmacol. 101, 971-977.

Chopra RN, Chopra IC, Handa KL, Kapoor LD. (1982) Indigenous drugs of India Academic publishers: Calcutta-New Delhi, pp. 293-294

Choudhry VP, Sabir M, Bhide VN. (1972) Berberine in giardiasis. Indian Pediatr 9, 143-146.

Del Castillo J, De Mello WC, Morales T. (1963) The Physiological role of acetylcholine in the neuromuscular system of Ascaris lumbricoides. Arch. Int. Physiol. Biochem. 71, 741-757.

Fetterer RH. (1986) Transcuticular solute movement in parasitic nematodes: relationship between non polar solute transport and partition coefficient. Comp. Biochem. Physiol. 84A, 461-466.

Hua WG, Song JM, Liao H et al. (2001) Effect of Huang Lian Su on nerve conduction velocity and hormone level to diabetic neuropathy in rats. Labeled immunoassays and Clin. Med. 8, 212-214 (In Chinese)

Hua Z, Wang XL. (1994) Inhibitory effect of berberine on potassium channels in guinea pig ventricular myocytes. Yaо Хие Хие Ваo 29, 576-580.

Lahiri SC, Dutta NK. (1967) Berberine and chloramphenicol in the treatment of cholera and severe diarrhoea. J. Indian Med. Assoc. 48, 1-11.

Martin BJ. (1982) Electrophysiological effects of piperazine and diethylcarbamazine on Ascaris somatic muscle. Br. J. Pharmacol. 77, 255-265.

Sharda DC. (1970) Berberine in the treatment of diarrhoea of infancy and childhood. J. Indian Med. Assoc. 54, 22-24.

Singhal KC, Madan BR, Saxena PN, Johri MBL. (1975) Effect of neurohormones and some other drugs on the movements of Setaria cervi. Indian J. Pharmacol. 7, 22-26.

Singhal KC, Zehra N, Singhal U, Saxena PN. (1978). Acetylcholine: A possible neurotransmitter in Setaria cervi. J. Physiol. Pharmacol. 22, 71-74. 